\title{
Detection of DNA copy number alterations in cancer by array comparative genomic hybridization
}

Evi Michels, MSc, Katleen De Preter, PhD, Nadine Van Roy, PhD, and Frank Speleman, PhD

\begin{abstract}
Over the past few years, various reliable platforms for high-resolution detection of DNA copy number changes have become widely available. Together with optimized protocols for labeling and hybridization and algorithms for data analysis and representation, this has lead to a rapid increase in the application of this technology in the study of copy number variation in the human genome in normal cells and copy number imbalances in genetic diseases, including cancer. In this review, we briefly discuss specific technical issues relevant for array comparative genomic hybridization analysis in cancer tissues. We specifically focus on recent successes of array comparative genomic hybridization technology in the progress of our understanding of oncogenesis in a variety of cancer types. A third section highlights the potential of sensitive genome-wide detection of patterns of DNA imbalances or molecular portraits for class discovery and therapeutic stratification. Genet Med 2007:9(9):574-584.
\end{abstract}

Key Words: Array CGH, cancer, genomics, copy number alteration, microarray, prognosis, therapy

\section{UNDERSTANDING CANCER THROUGH THE STUDY OF CANCER GENOMICS}

Cancer results from a series of genetic and epigenetic alterations that allow cells to become independent of growth signals, to escape growth inhibitory and apoptotic signals, to acquire unlimited growth potential, and ultimately to invade neighboring tissues and metastasize to other organs. ${ }^{1}$ In the past decades, research has been successful in identifying some of the genes controlling these cellular processes, thereby contributing to the unraveling of the genetic basis of cancer. A number of these genes emerged as key players with a central role in the tight control of cell cycle, apoptosis, and DNA repair. This multitude of genes controls networks of a restricted number of signaling pathways. Two such pathways, centering around the RB1 and TP53 genes, respectively, are assumed to be disrupted in virtually all cancer types. Other major signaling pathways perturbed in cancer include the RAS/MAP kinase (growth control), PI3/AKT (survival, apoptosis), TGF $\beta$, and JAK/STAT pathway. ${ }^{2}$ Cytogenetic and molecular genetic investigations provided insight into the plethora of mutations that disrupt the normal function of genes implicated in cancer. Proto-oncogenes are known to be activated through gain-offunction mutations at the base pair level or are over-expressed because of copy number gain, amplification, or translocation. Tumor suppressor genes can be inactivated by loss-of-function

From the Center for Medical Genetics, Ghent University Hospital, Ghent, Belgium. Frank Speleman, Center for Medical Genetics, Ghent University Hospital, Medical Research Building, De Pintelaan 185, B-9000 Ghent, Belgium; E-mail: Franki.Speleman@UGent.be Disclosure: The authors declare no conflicts of interest.

Submitted for publication May 14, 2007.

Accepted for publication June 13, 2007.

DOI: 10.1097/GIM.0b013e318145b25b mutations, deletions affecting one (haplo-insufficiency) or both alleles, or epigenetic modifications. A particular class of oncogenic events most often (but not exclusively) observed in leukemias, lymphomas, and soft tissue tumors are chromosome rearrangements causing in frame fusion of parts of two genes leading to the formation of hybrid genes with particular oncogenic properties. ${ }^{3}$

Classical cytogenetics has been extremely important in identifying such recurrent rearrangements, in particular recurrent translocations, which helped to uncover the position and allowed the molecular cloning of the genes implicated in such proto-oncogene activation or gene fusion events. ${ }^{3,4}$ This interplay between cytogenetic and molecular genetics allowed the generation of new tools for diagnosis and follow-up of the disease. Furthermore, the discovery of gene fusions represented the first step toward the unraveling of the pathogenesis of these particular cancers and, more importantly, for the development of molecular-targeted therapy.5,6 Treatment of chronic myeloid leukemia with the tyrosine kinase inhibitor imatinib illustrates how the identification of such cancer genes and perturbed signaling pathways revealed targets for less toxic and more efficient molecular therapy. 7,8

For some tumor entities, however, classical cytogenetics has been less successful because of the complexity of karyotypes or difficulty of culturing tumor cells in vitro. Chromosomal comparative genomic hybridization (CGH) opened the way for the study of DNA copy number alterations in such cancers. A particular advantage of this technique is that dividing cells are not required, allowing the study of archived material such as frozen biopsies or paraffin-embedded material. A large body of literature describes the findings by chromosomal CGH on such tumors, which contributed to the mapping of tumor suppressor genes and amplified proto-oncogenes and the identification of prognostically relevant genomic subclasses. ${ }^{9,10}$ The role 
of low copy number gain in cancer is still poorly studied, but evidence is accumulating that gain of one single copy of a gene, chromosomal region, or entire chromosome can effectively contribute to the tumor phenotype.

Because the original CGH procedure used chromosomes as the target for assessing DNA copy number alterations, the resolution of such analyses remained limited to approximately 5 to $10 \mathrm{Mb} .{ }^{11}$ The use of DNA clones spotted in array format on slides as targets for hybridization of normal and test DNA (array $\mathrm{CGH}$ ) opened the way for a dramatic increase in resolution up to $30 \mathrm{~kb}^{12}$ and more rapid and streamlined handling of assays, avoiding the tedious production of well-spread chromosome slides and subsequent karyotyping. As a result of these advantages, particularly the broader accessibility for laboratories to implement array CGH, this new technique has now become popular and widely applied, among other technologies for studying gains and losses in tumors. ${ }^{13-16}$ This widespread application in tumor genetics, however, only followed several years after the first technical reports describing the technique. ${ }^{13-15}$ This can be explained by the limited availability of good quality slides with a high density of probes. cDNA arrays were more readily available, but the rather low sensitivity makes averaging across multiple clones necessary for scoring gains and losses. ${ }^{11} \mathrm{BAC}$ clones were suitable alternatives as probes, ${ }^{17}$ but quality of spotted slides could vary greatly because of changes in temperature, humidity, BAC DNA concentration, and damage to spotting pins. The quality of sample and control DNA, batch variation of Cot I DNA, labeling, and hybridization conditions are also important factors for success. ${ }^{18}$ The availability of a $1-\mathrm{Mb}$ BAC set and exchange of experimental information during various meetings ${ }^{18}$ greatly triggered the dissemination of the technology. At the same time, the possibility of the use of SNP chips for assessment of DNA copy number alterations was discovered, ${ }^{19-22}$ and improved high-density oligonucleotide slides were produced, further broadening the accessibility of array CGH platforms and leading to a rapidly increasing number of laboratories successfully implementing this new technology. ${ }^{17,23-26}$

Several good reviews on array CGH have been published. ${ }^{16,27-30}$ In this review, we specifically discuss the present and future role of array CGH in the study of cancer genomes in relation to other emerging technologies. First, we discuss technical issues with particular relevance for array CGH in cancer. Next, we illustrate how array CGH is contributing to the identification of cancer genes and our understanding of molecular pathogenesis. Finally, we assess how tumor class discovery based on genomic molecular portraits can contribute to clinical management.

\section{TECHNICAL CONSIDERATIONS RELATED TO ARRAY CGH ANALYSIS OF TUMOR SAMPLES}

With array CGH procedures becoming more firmly established, DNA quality still remains a crucial factor in performing a successful array CGH experiment. In general, high molecular weight DNA can be easily obtained from fresh or frozen tumor material, but difference in quality can occur depending on the type of DNA isolation procedure. Therefore, when using kits for fast DNA isolation, an extra DNA purification step can be useful to further improve DNA quality. The issue of DNA quality is of particular importance for formalin-fixed paraffin-embedded tissue (FFPE) material. FFPE samples are of importance for cancer research, as they are often more readily available than frozen samples and thus represent an important source of archival tissue with long clinical follow-up. The major disadvantage to using FFPE samples is DNA degradation resulting from the type and duration of fixation. Procedures have been developed to obtain DNA of sufficient quality, but array CGH on such samples remains challenging and typically generates lower signal-to-noise ratios. Given the high cost of array CGH analysis, it is essential to reduce the number of failures to a minimum through assessing DNA quality before hybridization. Although a simple DNA gel electrophoresis can be performed for this evaluation, this may require too much valuable patient material and may also insufficiently predict samples compliancy for further analysis, indicating that parameters other than size are important for success. It has been demonstrated that DNA cross-linking because of the fixation procedure is also an important factor influencing DNA quality. Therefore, an optimized selection process was developed. This includes an improved DNA isolation protocol promoting DNA de-cross-linking, followed by multiplex PCRbased quality control to assess residual DNA cross-linking, resulting in a more precise estimation of archival samples suitable for array CGH analysis. ${ }^{31}$ Recently, another study published guidelines for qualifying FFPE DNA samples for genotyping, loss of heterozygosity, and copy number analysis, including random amplified polymorphic DNA-PCR as a critical evaluation step. ${ }^{32}$ In addition, commercial kits to determine the quality of genomic DNA isolated from FFPE tissue are becoming available. For example the BioScore screening and amplification kit (Enzo Life Sciences, Inc., NY) uses a novel whole-genome amplification method to predict sample performance. After this quality screening step, the amplified genomic DNA can be directly used for subsequent array analysis.

A second important issue in array CGH of cancer cells is contamination with normal cells. Spiking experiments, mixing various amounts of nontumoral DNA with a known glioblastoma xenograft sample containing known homozygous and heterozygous deletions, showed that array CGH of a sample with tumor cell percentage less than $50 \%$ agreed only poorly with genomic profiles obtained from 100\% tumoral DNA, with both chromosomal gains and losses being difficult to recognize. ${ }^{33}$ As a general guideline for tumor analysis, histological review should be performed on each tumor specimen to ensure sufficient tumor cell percentage and the absence of necrotic material.

It is also important to consider tumor ploidy when studying tumor genetics. In the case of near-triploid tumors, imbalances-in particular gains-may become more difficult to detect using standard thresholds. To resolve this problem, various ad- 
vanced algorithms have been developed, ${ }^{34}$ such as circular binary segmentation (CBS). ${ }^{35}$ This algorithm translates noisy intensity measurements into regions of equal copy number and thus can be very useful in detecting the copy number transitions (Fig. 1). CBS can also greatly increase the detection rate for copy number alterations in samples with a percentage of normal cells up to approximately 10 to $20 \%$. Recently, another algorithm was described that takes into account the nature of the noise in array CGH data to more accurately determine the regions of aberration and boundaries of breakpoints. ${ }^{36}$

Tumor heterogeneity is another factor that may complicate the interpretation of array CGH data. Furthermore, array CGH may not fully appreciate tumor heterogeneity as DNA copy number changes in a small number of cells will be diluted by the remainder of normal cells without copy number changes. Both the problem of normal contaminating cells and genetic heterogeneity of tumors can be addressed through the use of microdissection of clusters or individual tumor cells $\mathrm{s}^{37,38}$ followed by DNA amplification to produce sufficient DNA for labeling and hybridization (approximately $300 \mathrm{ng}$ to $2 \mu \mathrm{g}$ ). Such DNA amplification procedures are also valuable for processing and analysis of small tumor samples, e.g., obtained through needle biopsies. The increasing demand for robust and unbiased whole-genome amplification methods has triggered the development of several genome-wide protocols that can roughly be divided in variations of PCR amplification (including degenerate oligonucleotide-primed PCR, ${ }^{39}$ primer ex- tension preamplification, ${ }^{40}$ linker adaptor $\mathrm{PCR},{ }^{41}$ and interspersed repetitive sequence $\mathrm{PCR}^{42}$ ) and isothermal DNA amplification using the $\$ 29$ bacteriophage DNA polymerase (including rolling circle amplification ${ }^{43}$ and its derivative, multiple displacement amplification ${ }^{44}$ ). Although both PCR and isothermal amplification approaches generate several micrograms of amplified DNA from a small initial amount, the major challenge when combining whole-genome amplification techniques and high-resolution array CGH remains in obtaining an unbiased replication of all chromosomal regions. Several reports have already successfully used a combination of whole-genome amplification and array CGH analysis, with or without correction for amplification errors. ${ }^{33,45-50}$ An elegant example illustrating the power of whole-genome amplification is the isolation of DNA samples from the histopathologically heterogeneous mixture of discrete foci of invasive carcinoma and premalignant high-grade prostatic intraepithelial neoplasia. Subsequent amplification using multiple-displacement amplification and hybridization onto BAC arrays identified particular chromosomal changes associated with the two disease stages. ${ }^{51}$ An attractive novel method for whole-genome amplification is the Genomeplex technology (Sigma-Aldrich, UK), which uses random fragmentation and adaptor annealing via PCR to generate high-quality amplified DNA from a variety of sources (Fig. 2). Using this technology, it was recently shown that reliable genomic copy number profiles could be obtained even starting with a single cell..$^{52} \mathrm{~A}$ dedicated data

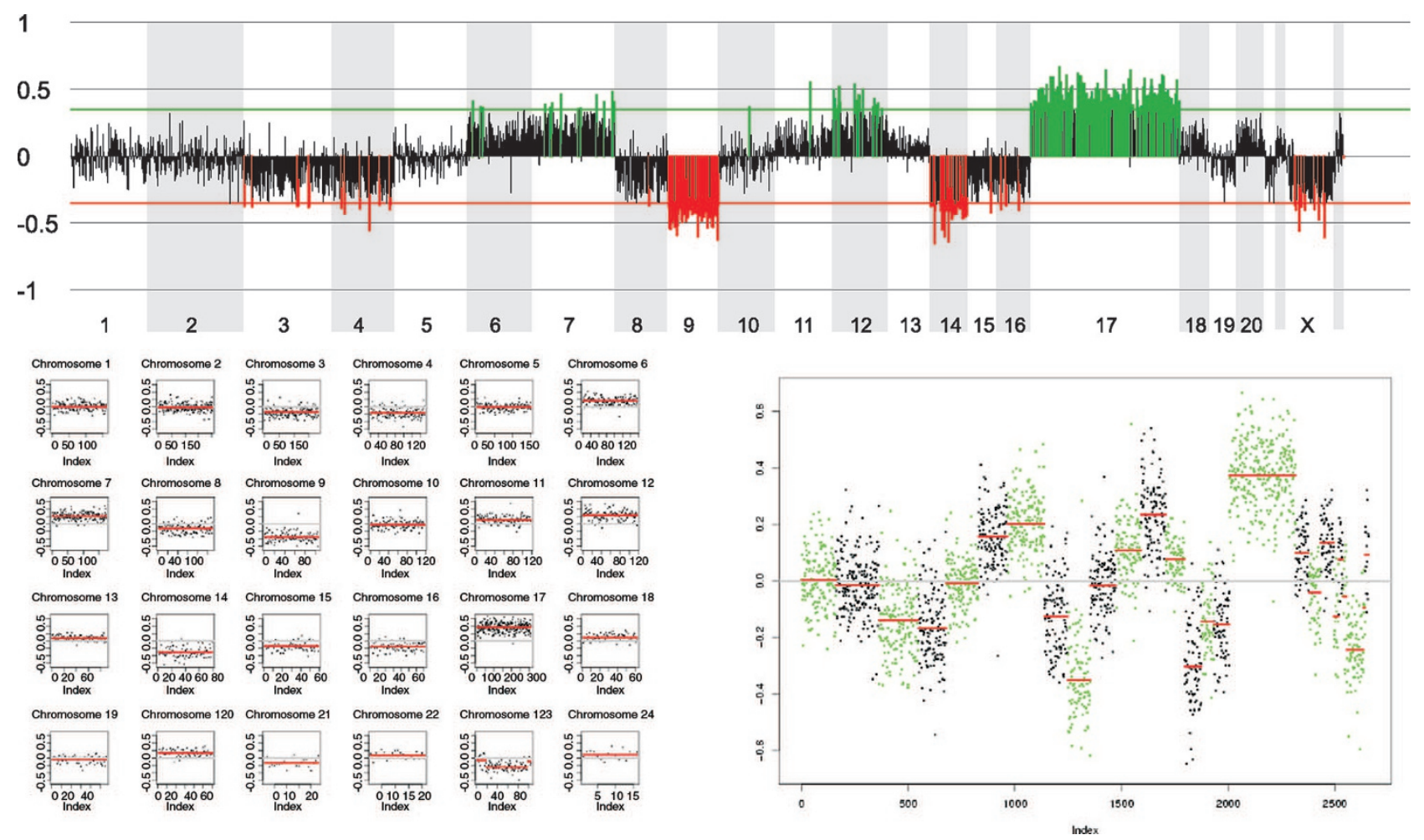

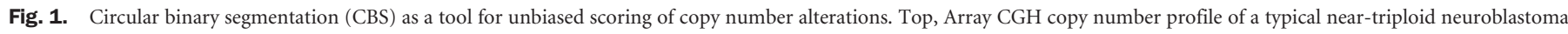

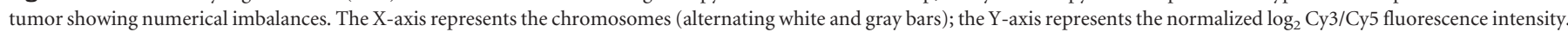

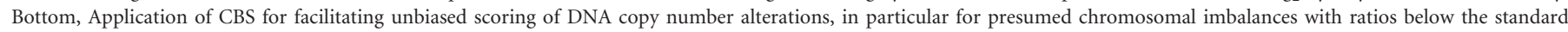
threshold, e.g., in hyperploid cells, heterogeneous samples, and samples with normal contaminating cells. 

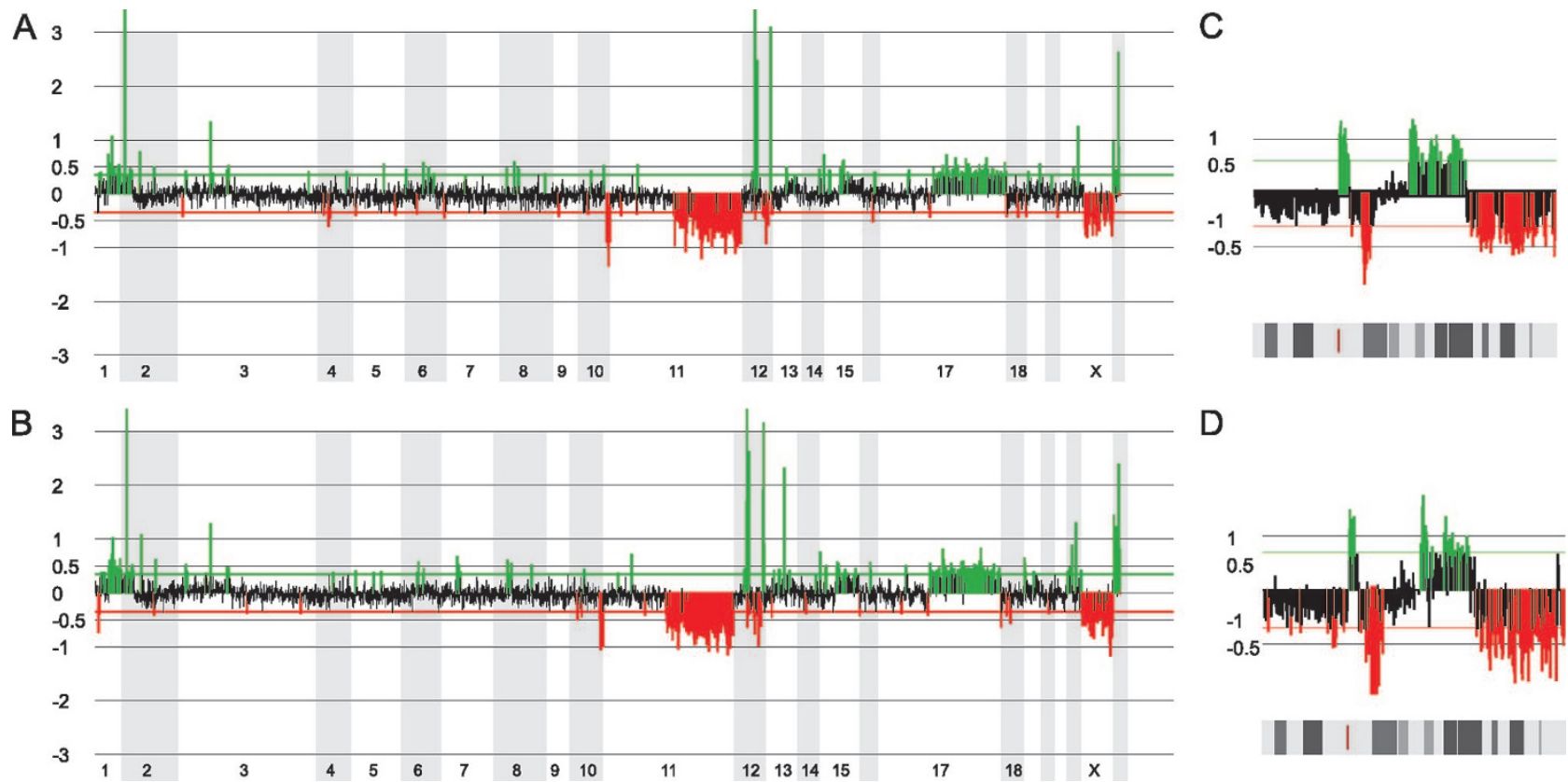

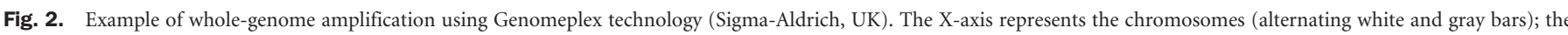

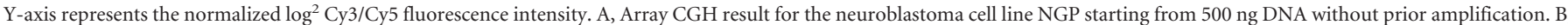

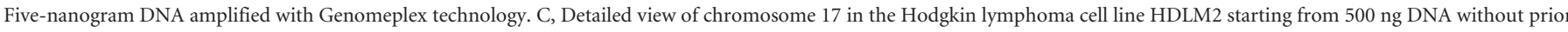
amplification. ${ }^{106}$ D, Five-nanogram DNA amplified with Genomeplex technology (Feys et al., personal communication).

analysis procedure allowed the detection of a single copy number aberration as small as $8.3 \mathrm{Mb}$, which is a remarkable increase in resolution compared with earlier experiments using multiple displacement amplification. ${ }^{53}$ Such analyses of isolated cell islets, or even single cells, offer great opportunities to study intratumor heterogeneity, tumor progression through analysis of premalignant and malignant foci, or genomic changes in metastasized cells.

\section{ARRAY CGH AS A TOOL FOR CANCER GENE DISCOVERY AND UNDERSTANDING DISEASE PATHOGENESIS}

\section{Dissecting amplicons}

In view of the knowledge that, in addition to mutations at the base pair level, larger genomic alterations contribute to the tumor phenotype by altering normal gene function, the search for such DNA imbalances has been an important part of ongoing cancer research, and array CGH has also been successful. From the beginning, array CGH studies have focused on the analysis of amplicons. Given the unprecedented resolution offered by array $\mathrm{CGH}$, this method turned out to be very powerful for dissecting highly amplified regions in cancer cell genomes. The interest in such amplicons can be explained by the fact that these regions may harbor novel proto-oncogenes that, upon activation, contribute to the aggressiveness of cancer cells, response to therapy, and development of resistance. Because those genes or components of the pathways they control can represent druggable targets, their identification in recurrent amplified chromosomal segments has remained a major research aim (Fig. 3). The promise amplifications hold for targeted therapy has triggered a myriad of articles dissecting amplicons to identify driver oncogenes and the pathways they disturb. ${ }^{54}$ It is impossible to review the entire existing literature on this topic, but we illustrate the possibilities of array CGH in the dissection of amplicons through a number of landmark articles and results from our own investigations in neuroblastoma. Amplicons in breast cancer are probably among the most intensively studied. Albertson et al ${ }^{55}$ reported that quantitative measurement of DNA copy numbers across amplified regions using array CGH facilitates identification of ZNF217 and CYP24 as oncogenes, based on mapping of amplicon boundaries and amplification maxima. Another example of a particular target gene identified through mapping of a 19q13 amplicon is the finding of the $I X L$ gene in pancreatic cancer as a cell survival regulator. ${ }^{56}$ Monni et al. ${ }^{57}$ used a combination of molecular, genomic, and microarray technologies to identify target genes within the 17q23 amplicon, a common region of amplification in breast cancers linked with poor prognosis. Two common regions of amplification were defined, and further expression analyses enabled the selection of a small number of consistently over-expressed genes. Various other studies have focused on the mapping of breast cancer amplicons in cell lines and primary tumors. ${ }^{58-63}$ In recent extensive studies, Neve et al. ${ }^{64}$ and Chin et al. ${ }^{65}$ report combined high-resolution DNA and expression profiling of 51 and 145 breast cancer cell lines and tumors, respectively. In tumors, nine recurrent amplicons on chromosomes $8,11,12,17$, and 20 were found, in keeping with previous studies ${ }^{14,66-69}$ with an indication for preferential co-amplification for certain regions. Using an in- 


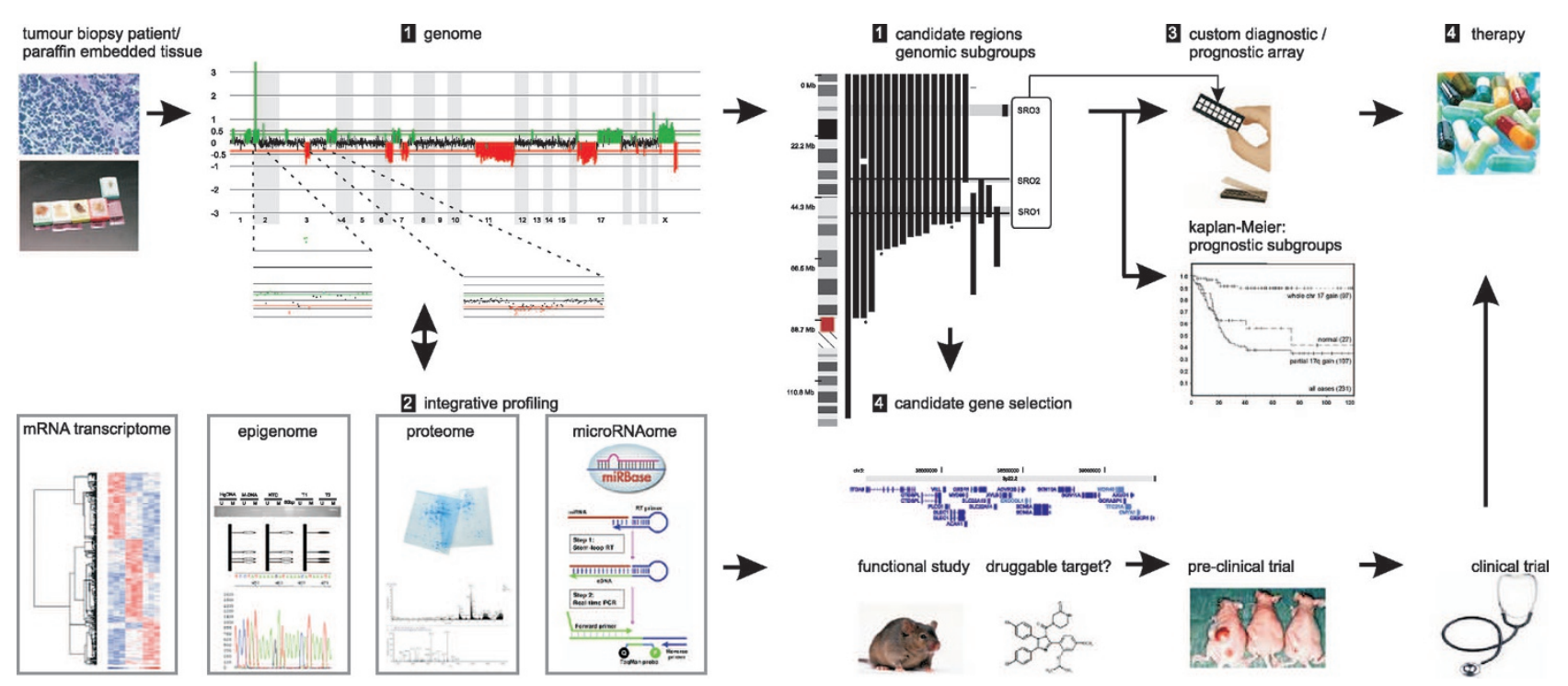

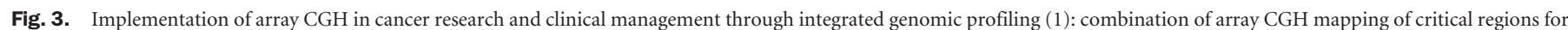

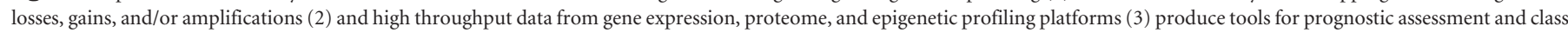
discovery (4) and lists of candidate genes for functional studies for understanding tumor biology and screening and testing of new therapeutic compounds.

tegrated approach, combining both expression and genomic data, a total of 66 over-expressed genes likely to be functionally important in these tumors was highlighted, a significant portion of which are high-priority therapeutic targets. ${ }^{64,65}$ These findings hold promise for patients whose disease does not respond to current aggressive therapies. ${ }^{65}$ For example, some of these genes reside in the HER2 amplicon and are co-activated with HER2. Manipulation of these genes could therefore trigger a synergistic therapeutic response, which could be beneficial for patients with a poor response to Herceptin. ${ }^{70}$

In addition to the classical amplicons encompassing larger genomic regions, which often encompass multiple genes, Holst et al. ${ }^{71}$ reported a single-gene amplification of the ESR1 gene, which encodes estrogen receptor alpha at $6 \mathrm{q} 25$ with further extended screening on tissue microarrays demonstrating ESR1 amplification in $20.6 \%$ of breast cancers. Of particular interest, amplification was also detected in benign and precancerous breast diseases, which could point to ESR1 amplification as a common mechanism in proliferative breast disease and a very early genetic alteration in a large subset of breast cancers. ${ }^{71}$

The importance of screening for amplicons in our understanding of tumor biology was recently illustrated by the detection of MDM4 amplification in retinoblastoma providing an explanation for suppression of TP53 activation in these tumors, by allowing them to escape from apoptotic signaling upon $R B 1$ inactivation. ${ }^{72}$

Neuroblastoma (NB), a childhood embryonal tumor, was one of the first tumors in which high-level DNA amplification was discovered. ${ }^{73}$ MYCN amplification was present in a specific subset of high-stage tumors with poor prognosis, and mapping studies indicated that $M Y C N$ was the only consistently amplified gene across all examined amplicons. ${ }^{74-76}$ Our research group has studied neuroblastoma using molecular cy- togenetic techniques and, more recently, array CGH. A series of 100 NB primary tumors and 29 cell lines were analyzed. This and other studies showed that, in addition to the frequently amplified MYCN proto-oncogene, other rare amplicons can also occur. Such observations further illustrate the genetic heterogeneity in these tumors. The occurrence of known amplicons, including CCND1 and MDM2, point at common oncogenic (progression) pathways in tumors. Previously undetected amplicons may also be found. ${ }^{77-79}$ Because of the possible prognostic impact of such findings, using sufficiently high-density arrays both for research and prognostic purposes is important (in keeping with the above mentioned ESR1 amplification in breast cancer).

In acute myeloid leukemia, amplicons are less frequently observed but, again, typically occur in aggressive forms. An example of the use of array CGH in the study for such amplicons was published by Baldus et al., ${ }^{80}$ who identified APP, ETS2, and ERG as over-expressed genes in chromosome 21derived amplicons. In a genome-wide array CGH study by Rucker et al., ${ }^{81}$ a more general role of proto-oncogene activation in acute myelogenous leukemia (AML) pathogenesis was suggested. As already indicated, fusion genes are important (but often not sufficient) genetic events driving oncogenesis. Although such additional genetic defects may accompany gene fusions such as PAX5 deletions in ETV6/RUNX-positive childhood acute lymphoblastic leukemias (ALLs), ${ }^{82}$ over-expression of the fusion product because of amplification can also increase aggressiveness of the tumor cell ${ }^{83}$ or lead to therapy resistance, as illustrated by $B C R / A B L 1$ amplifications in imatinib-treated chronic myelogenous leukemias. ${ }^{84}$

Despite our increasing knowledge of target genes within amplicons, the mechanisms leading to amplicon formation remain largely unresolved. ${ }^{54}$ The power of array CGH to unravel these mechanisms was shown in the study of a neuroblastoma 
cell line with amplified sequences in the absence of more common MYCN amplification. This study also illustrated that the combination of DNA array data and (M)-FISH analysis on metaphase slides allowed interpretation of array CGH data in the context of genomic position and complete characterization of a complex rearrangement leading to amplicon formation. The detection of a reciprocal $t(8 ; 16)$ translocation with breakpoints near co-amplified MYC (8q24) and ATBF1 (16q22.3q23.1) genes suggested that this translocation might have triggered amplicon formation through a complex process of translocation-excision-deletion-amplification mechanism leading to nonsyntenic amplification of MYC and ATBF1. ${ }^{85}$

\section{MAPPING DELETIONS IN SEARCH FOR TUMOR SUPPRESSOR GENES}

Array CGH has been extensively applied for fine mapping of deletions and identification of putatively involved tumor suppressor genes. Such studies have contributed to refinement of known critically deleted regions and have also enabled the detection of new regions of recurrent losses (Fig. 3). Clearly, the use of high- or even ultra high-resolution DNA arrays greatly facilitates accurate breakpoint mapping and, most importantly, allows the identification of small (homozygous) deletions. ${ }^{86-96}$

In our analysis of neuroblastoma tumors and cell lines, a $1-\mathrm{Mb} \mathrm{BAC}$ array was supplemented with tiling paths for recurrently deleted regions (1p, 3p, and 11q) and gains (17q). This approach resulted in a significantly improved delineation of the critical deleted regions on $3 p$, among others, through the detection of small interstitial deletions in neuroblastoma cell lines. In total, three regions of loss were delineated that were also known to be involved in more common epithelial neoplasms, thus providing support for the relevance of our findings in neuroblastoma. ${ }^{97-100}$ Stallings et al. ${ }^{91}$ detected recurrent deletions of a region on $9 \mathrm{p}$ encompassing the PTPRD locus, indicating a possible tumor suppressor function for this gene in neuroblastoma. Remarkably, shortly after this discovery, the same locus was found to be deleted in cutaneous squamous cell carcinomas. ${ }^{90}$ The finding of common genetic defects in both embryonal tumors, such as neuroblastoma and epithelial cancers, strongly suggests that similar molecular pathways are involved in these seemingly unrelated tumors. In Wilms tumor, another embryonal tumor of childhood, an unexpected small intrachromosomal deletion on the X-chromosome was detected, pointing to a role for the WTX gene in non-WT1 mutant tumors. ${ }^{101}$ As discussed previously, the full malignant phenotype of cancer cells results from multiple genetic defects. Keeping this in mind, Mullighan et al..$^{82}$ set out to search for previously unnoticed submicroscopic lesions in childhood ALL. This search uncovered the presence of mono-allelic deletions targeting the PAX5 gene in as many as $30 \%$ of all investigated ALL samples. Moreover, further investigation of non-deleted cases showed point mutations and cryptic translocations resulting in haplo-insufficiency for this gene. Furthermore, deletions affecting many other genes involved in pathways controlling B-cell development were found, firmly establishing the link be- tween cancer and cellular differentiation. ${ }^{82,102}$ Yet another example of the power of such high-resolution scanning of the cancer genome for deletions is the detection of a novel recurrent del (p12p13) in T-cell ALL (T-ALL), ${ }^{11}$ resulting in loss of a negative regulatory region upstream of $L M O 2$ and consequent activation of the $L M O 2$ promoter, representing a novel activation mechanism of $L M O 2$ in pediatric T-ALL. ${ }^{103}$ Furthermore, genome-wide SNP array technology in AML showed that approximately $20 \%$ of normal karyotype samples displayed previously unnoticed uniparental disomy for particular chromosome segments. ${ }^{104}$ Subsequent analysis identified homozygous mutations at distinct loci, indicating that isodisomy can play a role in rendering a leukemic cell homozygous for an existing mutation. ${ }^{105}$ Homozygous deletions are of particular interest in mapping tumor suppressor loci, as the affected region is relatively small, thus reducing the number of candidate tumor suppressor genes for further functional testing. Homozygous deletions were found through integrative genomic and geneexpression analyses in B-cell non-Hodgkin lymphoma (BNHL) and allowed the localization of 20 homozygous deletions at seven chromosome regions in 48 cell lines derived from patients with different B-NHLs, thereby identifying several new tumor suppressor gene targets. ${ }^{106}$ This and many other examples of small homozygous deletions have now been described as a result of the increased resolution of current array CGH platforms. ${ }^{86-89,91-95,107,108}$

\section{MAPPING GAINS IN THE SEARCH FOR DOSAGE-SENSITIVE PROTO-ONCOGENES}

Mapping of gains in genomic cancer research has thus far received little attention, but evidence is accumulating that such gains leading to a subtle increase in gene expression can indeed contribute to the cancer phenotype. Indirect evidence comes from developmental genetics, in which dosage effects resulting from single copy number changes (often deletions but sometimes duplications) are known to affect normal development. Given the involvement of developmental genes in cancer, similar effects at the cellular level can be expected in tumor genetics. In cancer cells, gains of chromosomes are a known recurrent defect. Trisomy can result in an extra copy of an activated proto-oncogene (e.g., MET109 and the MLL tandem duplication $^{110}$ ), but in most instances, the underlying pathogenetic mechanism and genes contributing to the tumor phenotype remain elusive. The longstanding and much debated hypothesis for a role of numerical aneuploidy in cancer development has found support through the observation that familial cancer may occur in individuals affected by $B U B 1$ mutations, leading to random gains and losses in somatic cells. ${ }^{111} \mathrm{~A}$ specific example for the importance of low copy gain of proto-oncogenes was provided by an array CGH study of T-ALL that reported a small duplication leading to increased expression of the $M Y B$ gene, disturbing normal differentiation of hematopoietic progenitor cells in a subset of T-ALL. ${ }^{12}$ Furthermore, identification of genes targeted by gains in a specific tumor can provide clues for other tumor entities, as shown in advanced serous 
epithelial ovarian cancers and breast cancers. ${ }^{113}$ High-density array CGH analysis identified a common 1.1-Mb region of copy number gain at 1q22 in approximately half of the advanced serous epithelial ovarian cancers and subsequently in breast cancers, leading to the identification of RAB25 small GTPase as a mediator of aggressiveness in both ovarian and breast cancers. ${ }^{113}$ In aggressive neuroblastomas, 17 q gain is the most frequent genomic imbalance, suggesting that dosagesensitive genes may be implicated. To refine the large region of common gain ( $35 \mathrm{Mb})$, we performed array CGH with a chromosome $17 \mathrm{BAC}$ tiling path array. In total, 52 different breakpoints were mapped at the resolution of a BAC, but no interstitial duplications, such as those detected in T-ALL, were found. We therefore looked for clusters of over-expressed genes using an integrated genomic approach, including gene expression data from both primary tumors (favorable vs. unfavorable) and normal fetal neuroblasts obtained through laser capture microdissection from fetal adrenal glands. ${ }^{114}$ Using an in-house-developed tool for positional gene enrichment analysis (PGE), we were able to identify regions that were significantly over-represented within a list of genes that are more highly expressed in neuroblastomas with $17 \mathrm{q}$ gain versus normal neuroblasts genes ${ }^{114}$ (De Preter, unpublished data). This PGE analysis revealed two regions that coincided with the boundaries obtained by mapping data for $17 \mathrm{q}$ gain using a chromosome $17 \mathrm{BAC}$ tiling path array, pointing to several candidate dosage-sensitive genes on chromosome 17 in neuroblastoma (Vandesompele et al., personal communication). Recently, it was shown that combined alterations in several genes may have a synergistic effect with a transforming capacity that cannot be obtained by any of the single gene defects. ${ }^{115}$ Likewise, it is possible that increase in dosage for several $17 \mathrm{q}$ genes leads to a synergistic effect. A possible test for such a hypothesis is combined knockdown of sets of dosage-sensitive genes in the critical region of gain. Similar integration of genome-wide copy number and expression data is a strategy to identify novel candidate genes (Fig. 3). Examples of this are found in B-cell lymphoma, ${ }^{106}$ lung cancer, ${ }^{116}$ glioblastoma, ${ }^{117}$ small cell lung cancer, ${ }^{118}$ non-small cell lung cancer, ${ }^{119}$ oral squamous cell carcinoma, ${ }^{120}$ glioblastoma, ${ }^{121}$ melanoma, ${ }^{122}$ and testicular germ cell neoplasm. ${ }^{123}$

\section{CROSS-SPECIES ONCOGENOMICS AND ANIMAL MODELS}

Although comparisons of genomic alterations between human and animal models have been criticized, some results now support the notion that such cross-species analysis can yield additional power to mapping studies. Two recent articles demonstrate the usefulness of comparative oncogenomics using mouse models with a defined genetic background to identify driver genes in oncogenesis and metastasis in human tumors. Integration of high-resolution copy number profiles of mouse tumor models and human tumors resulted in the discovery of the NEDD9 gene as a metastasis promoting gene in melanoma, whereas CIAP1 and YAP were identified as oncogenes in hepatocellular carcinoma. ${ }^{124,125}$ Further evidence illustrating the usefulness of cross-species comparisons comes from genomic analysis of the MYCN neuroblastoma mouse model, which revealed similar imbalances for syntenic chromosomal regions in mice and humans. ${ }^{126}$ Further study of the mouse model indicates that the development of these tumors is driven by similar genomic alterations and could therefore facilitate the identification of causal genes. Major advantages of tumors obtained from model organisms are that virtually unlimited amounts of material can be obtained and different stages in tumor development can be studied. This was first illustrated in a study by Hodgson et al., ${ }^{127}$ who showed that array CGH on murine carcinomas that develop in the pancreatic islets of transgenic mice could narrow down critical regions of interest and identify candidate oncogenes and tumor suppressor genes. Similar articles demonstrate the use of a murine lymphoma model, ${ }^{128}$ a mouse lung model, ${ }^{129}$ a mouse melanoma model, ${ }^{130}$ and mouse pheochromocytoma cell lines. ${ }^{131}$

\section{ARRAY CGH FROM BENCH TO BEDSIDE}

Beside the clues individual chromosome aberrations can provide toward cancer gene identification, the overall patterns of genomic aberrations (molecular portraits) also have intrinsic value and can provide a genomic framework for studying disease progression, tumor classification, and prognostic stratification. Tumor class discovery can become the starting point for a better comprehension of tumor biology and the development of different therapeutic strategies (Fig. 3). For example, using hierarchical clustering of oligonucleotide array data, it was recently shown that primary and secondary glioblastoma can be distinguished based on genomic aberrations. Moreover, two previously unappreciated genetically distinct cohorts were present within secondary glioblastoma. ${ }^{132}$ Similarly, clustering of neuroblastoma BAC array CGH data showed that only approximately $80 \%$ of neuroblastoma can be assigned to the three major clinical-genetic subgroups, indicating that genomic profiling could identify novel subgroups with possible clinical relevance. ${ }^{79}$

High-resolution genomic profiles generated by array CGH can also be directly useful in clinical practice. This was illustrated in lymphoma, in which diagnostic accuracy distinguishing Burkitts lymphoma from diffuse large B-cell lymphoma is crucial to prevent both over- and under-treatment. Using global gene expression and genomic profiling, Hummel et al. ${ }^{133}$ showed that Burkitt's lymphoma has a characteristic genetic signature that distinguishes it from cases of diffuse large B-cell lymphoma, allowing improved diagnostics and therapy choice. Targeted BAC/PAC diagnostic arrays are already constructed for B-cell chronic lymphocytic leukemia and $\mathrm{t}(11 ; 14)$ positive mantle cell lymphomas. ${ }^{134,135}$

Perhaps the most important challenge lies in assessing the prognostic power of molecular portraits for certain tumor entities, with or without taking into account other high-throughput clinically relevant information, such as coding gene and miRNA expression and methylation/chromatin modification profiles (Fig. 3). This approach was illustrated in a recent study 
of 148 primary breast cancers on a BAC platform consisting of a limited number of cancer-related loci. Even with this small number of probes, a molecular taxonomy of breast cancer samples could be generated with relevance toward survival. The presence of genomic molecular portraits predictive for clinical behavior has been described in a variety of tumor types, including neuroblastoma, ${ }^{79}$ gastric cancer, ${ }^{136}$ lymphoma, ${ }^{137}$ prostate cancer, ${ }^{138}$ muscle-invasive bladder cancers, ${ }^{139}$ and hereditary breast cancer. ${ }^{140}$ However, for many entities, larger numbers of samples are required to find signatures predictive for survival using array CGH. Therefore, a first step toward prognostic array CGH-based classification is collecting data from large series of clinically well-documented, homogenously treated patient tumor samples. Furthermore, it was shown that array CGH could also be of importance in differentiating (histologically) similar tumor entities, such as gastrointestinal stromal tumors versus leiomyosarcomas, ${ }^{141}$ CD4+CD65+ hematodermic neoplasm versus cutaneous myelomonocytic leukemia, ${ }^{142}$ and primary versus secondary glioblastoma. ${ }^{132}$

These data indicate the immediate clinical use of microarrays in tumor classification and differentiation. With the cost of array CGH analyses decreasing, it can be expected that such tests will become more widely available and will perhaps become an integral part of diagnostic tumor work-up more quickly than we anticipated.

\section{FUTURE PERSPECTIVES}

Array CGH is making a significant contribution to our further understanding of tumor biology. Increasing resolution of arrays now enables analysis of genomic regions even up to the single base pair level, indicating that complete characterization of numerous genes is coming within range. Similar results are being obtained using novel sequencing technologies, yielding equally exciting information and new insights. Understanding cancer will, however, require equally challenging profiling of transcriptome, miRNAome, epigenome, and proteome to fully comprehend complex tumor behavior. In addition, subtle regulatory variation, patient-specific susceptibility, tumor environment, and immunological response are other aspects currently recognized as contributing to the complex and heterogeneous tumor phenotype.

\section{ACKNOWLEDGMENTS}

NVR is a postdoctoral researcher of the Fund for Scientific Research (FWO), Flanders. KDP is a postdoctoral researcher of the Flemish Institute for the Promotion of Scientific Technological Research in Industry (IWT). This work was supported by the Kinderkankerfonds (a nonprofit childhood cancer foundation under Belgian law), The Fund for Scientific Research, Flanders ("Krediet aan Navorsers" project numbers1.5.243.05, 1.5.117.06 and 1.5.178.07), the "Stichting tegen Kanker" project number 365B0107, FWO-grant G.0185.04, BOF-grant 011F1200 and 011B4300, concerted research fund (GOA, nr. 12051203). This text presents research results of the
Belgian program of Interuniversity Poles of Attraction initiated by the Belgian State, Prime Minister's Office, Science Policy Programming and the European $6^{\text {th }}$ framework program EETpipeline.

\section{References}

1. Hanahan D, Weinberg RA. The hallmarks of cancer. Cell 2000;100:57-70.

2. Vogelstein B, Kinzler KW. Cancer genes and the pathways they control. Nat Med 2004;10:789-799.

3. Mitelman F, Johansson B, Mertens F. The impact of translocations and gene fusions on cancer causation. Nat Rev Cancer 2007;7:233-245.

4. Futreal PA, Coin L, Marshall M, Down T, et al. A census of human cancer genes. Nat Rev Cancer 2004;4:177-183.

5. Deininger M, Buchdunger E, Druker BJ. The development of imatinib as a therapeutic agent for chronic myeloid leukemia. Blood 2005;105:2640-2653.

6. Goldman JM, Melo JV. Chronic myeloid leukemia-advances in biology and new approaches to treatment. N Engl J Med 2003;349:1451-1464.

7. Collins I, Workman P. New approaches to molecular cancer therapeutics. Nat Chem Biol 2006;2:689-700.

8. Krause DS, Van Etten RA. Tyrosine kinases as targets for cancer therapy. N Engl J Med 2005;353:172-187.

9. Gebhart E. Comparative genomic hybridization (CGH): ten years of substantial progress in human solid tumor molecular cytogenetics. Cytogenet Genome Res 2004;104:352-358.

10. Gebhart E. Genomic imbalances in human leukemia and lymphoma detected by comparative genomic hybridization (Review). Int J Oncol 2005;27:593-606.

11. Mantripragada KK, Buckley PG, de Stahl TD, Dumanski JP. Genomic microarrays in the spotlight. Trends Genet 2004;20:87-94.

12. Coe BP, Ylstra B, Carvalho B, Meijer GA, et al. Resolving the resolution of array CGH. Genomics 2007;89:647-653.

13. Pinkel D, Segraves R, Sudar D, Clark S, et al. High resolution analysis of DNA copy number variation using comparative genomic hybridization to microarrays. Nat Genet 1998;20:207-211.

14. Pollack JR, Perou CM, Alizadeh AA, Eisen MB, et al. Genome-wide analysis of DNA copy-number changes using cDNA microarrays. Nat Genet 1999;23:41-46.

15. Solinas-Toldo S, Lampel S, Stilgenbauer S, Nickolenko J, et al. Matrix-based comparative genomic hybridization: biochips to screen for genomic imbalances. Genes Chromosomes Cancer 1997;20:399-407.

16. Speicher MR, Carter NP. The new cytogenetics: blurring the boundaries with molecular biology. Nat Rev Genet 2005;6:782-792.

17. Snijders AM, Nowak N, Segraves R, Blackwood S, et al. Assembly of microarrays for genome-wide measurement of DNA copy number. Nat Genet 2001;29:263-264.

18. Carter NP, Fiegler H, Piper J. Comparative analysis of comparative genomic hybridization microarray technologies: report of a workshop sponsored by the Wellcome Trust. Cytometry 2002;49:43-48.

19. Kennedy GC, Matsuzaki H, Dong S, Liu WM, et al. Large-scale genotyping of complex DNA. Nat Biotechnol 2003;21:1233-1237.

20. Lieberfarb ME, Lin M, Lechpammer M, Li C, et al. Genome-wide loss of heterozygosity analysis from laser capture microdissected prostate cancer using single nucleotide polymorphic allele (SNP) arrays and a novel bioinformatics platform dChipSNP. Cancer Res 2003;63:4781-4785.

21. Liu WM, Di X, Yang G, Matsuzaki H, et al. Algorithms for large-scale genotyping microarrays. Bioinformatics 2003;19:2397-2403.

22. Matsuzaki H, Loi H, Dong S, Tsai YY, et al. Parallel genotyping of over 10,000 SNPs using a one-primer assay on a high-density oligonucleotide array. Genome Res 2004;14:414-425.

23. Bignell GR, Huang J, Greshock J, Watt S, et al. High-resolution analysis of DNA copy number using oligonucleotide microarrays. Genome Res 2004;14:287-295.

24. Zhao X, Li C, Paez JG, Chin K, et al. An integrated view of copy number and allelic alterations in the cancer genome using single nucleotide polymorphism arrays. Cancer Res 2004;64:3060-3071.

25. Barrett MT, Scheffer A, Ben-Dor A, Sampas N, et al. Comparative genomic hybridization using oligonucleotide microarrays and total genomic DNA. Proc Natl Acad Sci USA 2004;101:17765-17770.

26. Carvalho B, Ouwerkerk E, Meijer GA, Ylstra B. High resolution microarray comparative genomic hybridisation analysis using spotted oligonucleotides. J Clin Pathol 2004;57:644-646.

27. Bejjani BA, Shaffer LG. Application of array-based comparative genomic hybridization to clinical diagnostics. J Mol Diagn 2006;8:528-533.

28. Lockwood WW, Chari R, Chi B, Lam WL. Recent advances in array comparative genomic hybridization technologies and their applications in human genetics. Eur J Hum Genet 2006;14:139-148. 
29. Pinkel D, Albertson DG. Array comparative genomic hybridization and its applications in cancer. Nat Genet 2005;37(Suppl):S11-17.

30. Ylstra B, van den Ijssel P, Carvalho B, Brakenhoff RH, et al. BAC to the future! Or oligonucleotides: a perspective for micro array comparative genomic hybridization (array CGH). Nucleic Acids Res 2006;34:445-450.

31. van Beers EH, Joosse SA, Ligtenberg MJ, Fles R, et al. A multiplex PCR predictor for aCGH success of FFPE samples. Br J Cancer 2006;94:333-337.

32. Jacobs S, Thompson ER, Nannya Y, Yamamoto G, et al. Genome-wide, highresolution detection of copy number, loss of heterozygosity, and genotypes from formalin-fixed, paraffin-embedded tumor tissue using microarrays. Cancer Res 2007;67:2544-2551.

33. Johnson NA, Hamoudi RA, Ichimura K, Liu L, et al. Application of array CGH on archival formalin-fixed paraffin-embedded tissues including small numbers of microdissected cells. Lab Invest 2006;86:968-978.

34. Lai WR, Johnson MD, Kucherlapati R, Park PJ. Comparative analysis of algorithms for identifying amplifications and deletions in array CGH data. Bioinformatics 2005;21:3763-3770.

35. Olshen AB, Venkatraman ES, Lucito R, Wigler M. Circular binary segmentation for the analysis of array-based DNA copy number data. Biostatistics 2004;5:557572.

36. $\mathrm{Hu}$ J, Gao JB, Cao Y, Bottinger E, et al. Exploiting noise in array CGH data to improve detection of DNA copy number change. Nucleic Acids Res 2007;35:e35.

37. Emmert-Buck MR, Bonner RF, Smith PD, Chuaqui RF, et al. Laser capture microdissection. Science 1996;274:998-1001.

38. Micke P, Ostman A, Lundeberg J, Ponten F. Laser-assisted cell microdissection using the PALM system. Methods Mol Biol 2005;293:151-166.

39. Telenius H, Carter NP, Bebb CE, Nordenskjold M, et al. Degenerate oligonucleotide-primed PCR: general amplification of target DNA by a single degenerate primer. Genomics 1992;13:718-725.

40. Zhang L, Cui X, Schmitt K, Hubert R, et al. Whole genome amplification from a single cell: implications for genetic analysis. Proc Natl Acad Sci USA 1992;89:58475851.

41. Lucito R, Nakimura M, West JA, Han Y, et al. Genetic analysis using genomic representations. Proc Natl Acad Sci USA 1998;95:4487-4492.

42. Lichter P, Ledbetter SA, Ledbetter DH, Ward DC. Fluorescence in situ hybridization with Alu and L1 polymerase chain reaction probes for rapid characterization of human chromosomes in hybrid cell lines. Proc Natl Acad Sci USA 1990;87:66346638 .

43. Lizardi PM, Huang X, Zhu Z, Bray-Ward P, et al. Mutation detection and singlemolecule counting using isothermal rolling-circle amplification. Nat Genet 1998; 19:225-232

44. Dean FB, Nelson JR, Giesler TL, Lasken RS. Rapid amplification of plasmid and phage DNA using Phi 29 DNA polymerase and multiply-primed rolling circle amplification. Genome Res 2001;11:1095-1099.

45. Bredel M, Bredel C, Juric D, Kim Y, et al. Amplification of whole tumor genomes and gene-by-gene mapping of genomic aberrations from limited sources of freshfrozen and paraffin-embedded DNA. J Mol Diagn 2005;7:171-182.

46. Cardoso J, Molenaar L de Menezes RX, Rosenberg C, et al. Genomic profiling by DNA amplification of laser capture microdissected tissues and array CGH. Nucleic Acids Res 2004;32:e146.

47. Daigo Y, Chin SF, Gorringe KL, Bobrow LG, et al. Degenerate oligonucleotide primed-polymerase chain reaction-based array comparative genomic hybridization for extensive amplicon profiling of breast cancers: a new approach for the molecular analysis of paraffin-embedded cancer tissue. Am J Pathol 2001; 158:1623-1631.

48. Guillaud-Bataille M, Valent A, Soularue P, Perot C, et al. Detecting single DNA copy number variations in complex genomes using one nanogram of starting DNA and BAC-array CGH. Nucleic Acids Res 2004;32:e112.

49. Lage JM, Leamon JH, Pejovic T, Hamann S, et al. Whole genome analysis of genetic alterations in small DNA samples using hyperbranched strand displacement amplification and array-CGH. Genome Res 2003;13:294-307.

50. Lovmar L, Fredriksson M, Liljedahl U, Sigurdsson S, et al. Quantitative evaluation by minisequencing and microarrays reveals accurate multiplexed SNP genotyping of whole genome amplified DNA. Nucleic Acids Res 2003;31:e129.

51. Hughes S, Yoshimoto M, Beheshti B, Houlston RS, et al. The use of whole genome amplification to study chromosomal changes in prostate cancer: insights into genome-wide signature of preneoplasia associated with cancer progression. BMC Genomics 2006;7:65.

52. Fiegler H, Geigl JB, Langer S, Rigler D, et al. High resolution array-CGH analysis of single cells. Nucleic Acids Res 2007;35:e15.

53. Le Caignec C, Spits C, Sermon K, De Rycke M, et al. Single-cell chromosomal imbalances detection by array CGH. Nucleic Acids Res 2006;34:e68.

54. Albertson DG. Gene amplification in cancer. Trends Genet 2006;22:447-455.
55. Albertson DG, Ylstra B, Segraves R, Collins C, et al. Quantitative mapping of amplicon structure by array CGH identifies CYP24 as a candidate oncogene. Nat Genet 2000;25:144-146.

56. Kuuselo R, Savinainen K, Azorsa DO, Basu GD, et al. Intersex-like (IXL) is a cell survival regulator in pancreatic cancer with 19q13 amplification. Cancer Res 2007; 67:1943-1949.

57. Monni O, Barlund M, Mousses S, Kononen J, et al. Comprehensive copy number and gene expression profiling of the $17 \mathrm{q} 23$ amplicon in human breast cancer. Proc Natl Acad Sci USA 2001;98:5711-5716.

58. Callagy G, Pharoah P, Chin SF, Sangan T, et al. Identification and validation of prognostic markers in breast cancer with the complementary use of array-CGH and tissue microarrays. J Pathol 2005;205:388-396.

59. Garcia MJ, Pole JC, Chin SF, Teschendorff A, et al. A $1 \mathrm{Mb}$ minimal amplicon at 8p11-12 in breast cancer identifies new candidate oncogenes. Oncogene 2005;24: $5235-5245$.

60. Hyman E, Kauraniemi P, Hautaniemi S, Wolf M, et al. Impact of DNA amplification on gene expression patterns in breast cancer. Cancer Res 2002;62:6240-6245.

61. Kauraniemi P, Barlund M, Monni Kallioniemi O, New amplified and highly expressed genes discovered in the ERBB2 amplicon in breast cancer by cDNA microarrays. Cancer Res 2001;61:8235-8240.

62. Parssinen J, Kuukasjarvi T, Karhu Kallioniemi R, High-level amplification at 17q23 leads to coordinated overexpression of multiple adjacent genes in breast cancer. Br J Cancer 2007;96:1258-1264.

63. Ray ME, Yang ZQ, Albertson D, Kleer CG, et al. Genomic and expression analysis of the 8p11-12 amplicon in human breast cancer cell lines. Cancer Res 2004;64: $40-47$.

64. Neve RM, Chin K, Fridlyand J, Yeh J, et al. A collection of breast cancer cell lines for the study of functionally distinct cancer subtypes. Cancer Cell 2006;10:515-527.

65. Chin K, DeVries S, Fridlyand J, Spellman PT, et al. Genomic and transcriptional aberrations linked to breast cancer pathophysiologies. Cancer Cell 2006;10:529541.

66. Kallioniemi A, Kallioniemi OP, Piper J, Tanner M, et al. Detection and mapping of amplified DNA sequences in breast cancer by comparative genomic hybridization. Proc Natl Acad Sci USA 1994;91:2156-2160.

67. Loo LW, Grove DI, Williams EM, Neal CL, et al. Array comparative genomic hybridization analysis of genomic alterations in breast cancer subtypes. Cancer Res 2004;64:8541-8549.

68. Naylor TL, Greshock J, Wang Y, Colligon T, et al. High resolution genomic analysis of sporadic breast cancer using array-based comparative genomic hybridization. Breast Cancer Res 2005;7:R1186-1198.

69. Pollack JR, Sorlie T, Perou CM, Rees CA, et al. Microarray analysis reveals a major direct role of DNA copy number alteration in the transcriptional program of human breast tumors. Proc Natl Acad Sci USA 2002;99:12963-12968.

70. Edgren H, Kallioniemi O. Integrated breast cancer genomics. Cancer Cell 2006;10: 453-454.

71. Holst F, Stahl PR, Ruiz C, Hellwinkel O, et al. Estrogen receptor alpha (ESR1) gene amplification is frequent in breast cancer. Nat Genet 2007;39:655-660.

72. Laurie NA, Donovan SL, Shih CS, Zhang J, et al. Inactivation of the $\mathrm{p} 53$ pathway in retinoblastoma. Nature 2006;444:61-66.

73. Schwab M, Varmus HE, Bishop JM, Grzeschik KH, et al. Chromosome localization in normal human cells and neuroblastomas of a gene related to c-myc. Nature 1984;308:288-291.

74. Brodeur GM, Seeger RC, Schwab M, Varmus HE, et al. Amplification of N-myc in untreated human neuroblastomas correlates with advanced disease stage. Science 1984;224:1121-1124.

75. Seeger RC, Brodeur GM, Sather H, Dalton A, et al. Association of multiple copies of the N-myc oncogene with rapid progression of neuroblastomas. $N$ Engl J Med 1985;313:1111-1116.

76. Vandesompele J, Baudis M, De Preter,K, Van Roy N, et al. Unequivocal delineation of clinicogenetic subgroups and development of a new model for improved outcome prediction in neuroblastoma. J Clin Oncol 2005;23:2280-2299.

77. De Preter K, Pattyn F, Berx G, Strumane K, et al. Combined subtractive cDNA cloning and array CGH: an efficient approach for identification of overexpressed genes in DNA amplicons. BMC Genomics 2004;5:11.

78. Michels E, Vandesompele J, Hoebeeck J, Menten B, et al. Genome wide measurement of DNA copy number changes in neuroblastoma: dissecting amplicons and mapping losses, gains and breakpoints. Cytogenet Genome Res 2006;115:273-282.

79. Michels E, Vandesompele J, De Preter K, Hoebeeck J, et al. Array CGH based classification of neuroblastoma into genomic subgroups. Genes Chromosomes Cancer. In press.

80. Baldus CD, Liyanarachchi S, Mrozek K, Auer H, et al. Acute myeloid leukemia with complex karyotypes and abnormal chromosome 21: Amplification discloses overexpression of APP, ETS2, and ERG genes. Proc Natl Acad Sci USA 2004;101:39153920 
81. Rucker FG, Bullinger L, Schwaenen C, Lipka DB, et al. Disclosure of candidate genes in acute myeloid leukemia with complex karyotypes using microarray-based molecular characterization. J Clin Oncol 2006;24:3887-3894.

82. Mullighan CG, Goorha S, Radtke I, Miller CB, et al. Genome-wide analysis of genetic alterations in acute lymphoblastic leukaemia. Nature 2007;446:758-764.

83. Graux C, Cools J, Melotte C, Quentmeier H, et al. Fusion of NUP214 to ABL1 on amplified episomes in T-cell acute lymphoblastic leukemia. Nat Genet 2004;36: 1084-1089.

84. Ren R. Mechanisms of BCR-ABL in the pathogenesis of chronic myelogenous leukaemia. Nat Rev Cancer 2005;5:172-183.

85. Van Roy N, Vandesompele J, Menten B, Nilsson H, et al. Translocation-excisiondeletion-amplification mechanism leading to nonsyntenic coamplification of MYC and ATBF1. Genes Chromosomes Cancer 2006;45:107-117.

86. Calhoun ES, Hucl T, Gallmeier E, West KM, et al. Identifying allelic loss and homozygous deletions in pancreatic cancer without matched normals using highdensity single-nucleotide polymorphism arrays. Cancer Res 2006;66:7920-7928.

87. Ichimura K, Mungall AJ, Fiegler H, Pearson DM, et al. Small regions of overlapping deletions on 6q26 in human astrocytic tumours identified using chromosome 6 tile path array-CGH. Oncogene 2006;25:1261-1271.

88. Izumi H, Inoue J, Yokoi S, Hosoda $\mathrm{H}$, et al. Frequent silencing of $\mathrm{DBC} 1$ is by genetic or epigenetic mechanisms in non-small cell lung cancers. Hum Mol Genet 2005; 14 997-1007.

89. Nakaya K, Yamagata HD, Arita N, Nakashiro KI, et al. Identification of homozygous deletions of tumor suppressor gene FAT in oral cancer using CGH-array. Oncogene. In press.

90. Purdie KJ, Lambert SR, Teh MT, Chaplin T, et al. Allelic imbalances and microdeletions affecting the PTPRD gene in cutaneous squamous cell carcinomas detected using single nucleotide polymorphism microarray analysis. Genes Chromosomes Cancer 2007;46:661-669.

91. Stallings RL, Nair P, Maris JM, Catchpoole D, et al. High-resolution analysis of chromosomal breakpoints and genomic instability identifies PTPRD as a candidate tumor suppressor gene in neuroblastoma. Cancer Res 2006;66:3673-3680.

92. Stark M, Hayward N. Genome-wide loss of heterozygosity and copy number analysis in melanoma using high-density single-nucleotide polymorphism arrays. Cancer Res 2007;67:2632-2642.

93. Tagawa H, Karnan S, Suzuki R, Matsuo K, et al. Genome-wide array-based CGH for mantle cell lymphoma: identification of homozygous deletions of the proapoptotic gene BIM. Oncogene 2005;24:1348-1358.

94. Takada H, Imoto I, Tsuda H, Nakanishi Y, et al. ADAM23, a possible tumor suppressor gene, is frequently silenced in gastric cancers by homozygous deletion or aberrant promoter hypermethylation. Oncogene 2005;24:8051-8060.

95. Weber RG, Hoischen A, Ehrler M, Zipper P, et al. Frequent loss of chromosome 9, homozygous CDKN2A/p14(ARF)/CDKN2B deletion and low TSC1 mRNA expression in pleomorphic xanthoastrocytomas. Oncogene 2007;26:1088-1097.

96. Zhao X, Weir BA, LaFramboise T, Lin M, et al. Homozygous deletions and chromosome amplifications in human lung carcinomas revealed by single nucleotide polymorphism array analysis. Cancer Res 2005;65:5561-5570.

97. Hoebeeck J, Michels E, Menten B, Van Roy N, et al. High resolution tiling-path BAC array deletion mapping suggests commonly involved 3p21-p22 tumor suppressor genes in neuroblastoma and more frequent tumors. Int J Cancer 2007;120: 533-538.

98. Sekido Y, Ahmadian M, Wistuba II, Latif F, et al. Cloning of a breast cancer homozygous deletion junction narrows the region of search for a 3 p21.3 tumor suppressor gene. Oncogene 1998;16:3151-3157.

99. Alimov A, Kost-Alimova M, Liu J, Li C, et al. Combined LOH/CGH analysis proves the existence of interstitial 3p deletions in renal cell carcinoma. Oncogene 2000;19: 1392-1399.

100. Braga E, Senchenko V, Bazov I, Loginov W, et al. Critical tumor-suppressor gene regions on chromosome $3 \mathrm{P}$ in major human epithelial malignancies: allelotyping and quantitative real-time PCR. Int J Cancer 2002;100:534-541.

101. Rivera MN, Kim WJ, Wells J, Driscoll DR, et al. An X chromosome gene, WTX, is commonly inactivated in Wilms tumor. Science 2007;315:642-645.

102. Golub TR. Genomics: global views of leukaemia. Nature 2007;446:739-740.

103. Van Vlierberghe P, van Grotel M, Beverloo HB, Lee C, et al. The cryptic chromosomal deletion del(11)(p12p13) as a new activation mechanism of LMO2 in pediatric T-cell acute lymphoblastic leukemia. Blood 2006;108:3520-3529.

104. Raghavan M, Lillington DM, Skoulakis S, Debernardi S, et al. Genome-wide single nucleotide polymorphism analysis reveals frequent partial uniparental disomy due to somatic recombination in acute myeloid leukemias. Cancer Res 2005;65:375378.

105. Fitzgibbon J, Smith LL, Raghavan M, Smith ML, et al. Association between acquired uniparental disomy and homozygous gene mutation in acute myeloid leukemias. Cancer Res 2005;65:9152-9154.
106. Mestre-Escorihuela C, Rubio-Moscardo F, Richter JA, Siebert R, et al. Homozygous deletions localize novel tumor suppressor genes in B-cell lymphomas. Blood 2007;109:271-280.

107. Feys T, Poppe B, De Preter K, Van Roy N, et al. A detailed inventory of DNA copy number alterations in four commonly used Hodgkin lymphoma cell lines. Haematologica 2007;92:913-920.

108. Hameetman L, Szuhai K, Yavas A, Knijnenburg J, et al. The role of EXT1 in nonhereditary osteochondroma: identification of homozygous deletions. J Natl Cancer Inst 2007;99:396-406.

109. Zhuang Z, Park WS, Pack S, Schmidt L, et al. Trisomy 7-harbouring non-random duplication of the mutant MET allele in hereditary papillary renal carcinomas. Nat Genet 1998;20:66-69.

110. Caligiuri MA, Schichman SA, Strout MP, Mrozek K, et al. Molecular rearrangement of the ALL-1 gene in acute myeloid leukemia without cytogenetic evidence of 11q23 chromosomal translocations. Cancer Res 1994;54:370-373.

111. Cahill DP, Lengauer C, Yu J, Riggins GJ, et al. Mutations of mitotic checkpoin genes in human cancers. Nature 1998;392:300-303.

112. Lahortiga I, De Keersmaecker K, Van Vlierberghe P, Graux C, et al. Duplication of the MYB oncogene in T cell acute lymphoblastic leukemia. Nat Genet 2007;39:593595.

113. Cheng KW, Lahad JP, Kuo WL, Lapuk A, et al. The RAB25 small GTPase determines aggressiveness of ovarian and breast cancers. Nat Med 2004;10:1251-1256.

114. De Preter K, Vandesompele J, Heimann P, Yigit N, et al. Human fetal neuroblast and neuroblastoma transcriptome analysis confirms neuroblast origin and highlights neuroblastoma candidate genes. Genome Biol 2006;7:R84

115. Christofori G. Cancer: division of labour. Nature 2007;446:735-736

116. Tonon G, Wong KK, Maulik G, Brennan C, et al. High-resolution genomic profiles of human lung cancer. Proc Natl Acad Sci USA 2005;102:9625-9630.

117. Ruano Y, Mollejo M, Ribalta T, Fiano C, et al. Identification of novel candidate target genes in amplicons of Glioblastoma multiforme tumors detected by expression and CGH microarray profiling. Mol Cancer 2006;5:39.

118. Kim YH, Girard L, Giacomini CP, Wang P, et al. Combined microarray analysis of small cell lung cancer reveals altered apoptotic balance and distinct expression signatures of MYC family gene amplification. Oncogene 2006;25:130-138.

119. Dehan E, Ben-Dor A, Liao W, Lipson D, et al. Chromosomal aberrations and gene expression profiles in non-small cell lung cancer. Lung Cancer 2007;56:175-184.

120. Snijders AM, Schmidt BL, Fridlyand J, Dekker N, et al. Rare amplicons implicate frequent deregulation of cell fate specification pathways in oral squamous cell carcinoma. Oncogene 2005;24:4232-4242.

121. Nigro JM, Misra A, Zhang L, Smirnov I, et al. Integrated array-comparative genomic hybridization and expression array profiles identify clinically relevant molecular subtypes of glioblastoma. Cancer Res 2005;65:1678-1686.

122. Garraway LA, Widlund HR, Rubin MA, Getz G, et al. Integrative genomic analyses identify MITF as a lineage survival oncogene amplified in malignant melanoma. Nature 2005;436:117-122.

123. Skotheim RI, Autio R, Lind GE, Kraggerud SM, et al. Novel genomic aberrations in testicular germ cell tumors by array-CGH, and associated gene expression changes. Cell Oncol 2006;28:315-326.

124. Kim M, Gans JD, Nogueira C, Wang A, et al. Comparative oncogenomics identifies NEDD9 as a melanoma metastasis gene. Cell 2006;125:1269-1281.

125. Zender L, Spector MS, Xue W, Flemming P, et al. Identification and validation of oncogenes in liver cancer using an integrative oncogenomic approach. Cell 2006; 125:1253-1267.

126. Hackett CS, Hodgson JG, Law ME, Fridlyand J, et al. Genome-wide array CGH analysis of murine neuroblastoma reveals distinct genomic aberrations which parallel those in human tumors. Cancer Res 2003;63:5266-5273.

127. Hodgson G, Hager JH, Volik S, Hariono S, et al. Genome scanning with array CGH delineates regional alterations in mouse islet carcinomas. Nat Genet 2001;29:459-464.

128. Sander S, Bullinger L, Karlsson A, Giuriato S, et al. Comparative genomic hybridization on mouse cDNA microarrays and its application to a murine lymphoma model. Oncogene 2005;24:6101-6107.

129. Sweet-Cordero A, Tseng GC, You H, Douglass M, et al. Comparison of gene expression and DNA copy number changes in a murine model of lung cancer. Genes Chromosomes Cancer 2006;45:338-348.

130. O'Hagan RC, Brennan CW, Strahs A, Zhang X, et al. Array comparative genome hybridization for tumor classification and gene discovery in mouse models of malignant melanoma. Cancer Res 2003;63:5352-5356.

131. Powers JF, Tischler AS, Mohammed M, Naeem R. Microarray-based comparative genomic hybridization of pheochromocytoma cell lines from neurofibromatosis knockout mice reveals genetic alterations similar to those in human pheochromocytomas. Cancer Genet Cytogenet 2005;159:27-31.

132. Maher EA, Brennan C, Wen PY, Durso L, et al. Marked genomic differences charac terize primary and secondary glioblastoma subtypes and identify two distinct molecular and clinical secondary glioblastoma entities. Cancer Res 2006;66:11502-11513. 
133. Hummel M, Bentink S, Berger H, Klapper W, et al. A biologic definition of Burkitt's lymphoma from transcriptional and genomic profiling. N Engl J Med 2006; 354:2419-2430.

134. Schwaenen C, Nessling M, Wessendorf S, Salvi T, et al. Automated array-based genomic profiling in chronic lymphocytic leukemia: development of a clinical tool and discovery of recurrent genomic alterations. Proc Natl Acad Sci USA 2004;101: 1039-1044.

135. Holzmann K, Kohlhammer H, Schwaenen C, Wessendorf S, et al. Genomic DNAchip hybridization reveals a higher incidence of genomic amplifications in pancreatic cancer than conventional comparative genomic hybridization and leads to the identification of novel candidate genes. Cancer Res 2004;64:4428-4433.

136. Weiss MM, Kuipers EJ, Postma C, Snijders AM, et al. Genomic alterations in primary gastric adenocarcinomas correlate with clinicopathological characteristics and survival. Cell Oncol 2004;26:307-317.

137. Rubio-Moscardo F, Climent J, Siebert R, Piris MA, et al. Mantle-cell lymphoma genotypes identified with CGH to BAC microarrays define a leukemic subgroup of disease and predict patient outcome. Blood 2005;105:4445-4454.
138. Paris PL, Andaya A, Fridlyand J, Jain AN, et al. Whole genome scanning identifies genotypes associated with recurrence and metastasis in prostate tumors. Hum Mol Genet 2004;13:1303-1313.

139. Blaveri E, Brewer JL, Roydasgupta R, Fridlyand J, et al. Bladder cancer stage and outcome by array-based comparative genomic hybridization. Clin Cancer Res 2005;11:7012-7022.

140. Jonsson G, Naylor TL, Vallon-Christersson J, Staaf J, et al. Distinct genomic profiles in hereditary breast tumors identified by array-based comparative genomic hybridization. Cancer Res 2005;65:7612-7621.

141. Meza-Zepeda LA, Kresse SH, Barragan-Polania AH, Bjerkehagen B, et al. Array comparative genomic hybridization reveals distinct DNA copy number differences between gastrointestinal stromal tumors and leiomyosarcomas. Cancer Res 2006; 66:8984-8993.

142. Dijkman R, van Doorn R, Szuhai K, Willemze R, et al. Gene-expression profiling and array-based CGH classify CD4+CD56+ hematodermic neoplasm and cutaneous myelomonocytic leukemia as distinct disease entities. Blood 2007;109:17201727. 